\title{
Regulation of SIRT3 signal related metabolic reprogramming in gastric cancer by Helicobacter pylori oncoprotein CagA
}

\author{
Do Yeon Lee ${ }^{1}$, Dawoon E. Jung ${ }^{2}$, Sung Sook Yư ${ }^{3}$, Yeo Song Lee $^{4}$, Beom Ku Choi ${ }^{5}$ \\ and Yong Chan Lee ${ }^{1}$ \\ ${ }^{1}$ Department of Internal Medicine, Yonsei University College of Medicine, Seoul, Korea \\ ${ }^{2}$ Institute of Gastroenterology, Yonsei University College of Medicine, Seoul, Korea \\ ${ }^{3}$ Department of Biomedical Science, Yonsei University College of Medicine, Seoul, Korea \\ ${ }^{4}$ Samsung Medical Research Center, Seoul, Korea \\ ${ }^{5}$ Immune \& Cell Therapy Branch, Division of Cancer Biology, National Cancer Center, Gyeonggi-do, Korea \\ Correspondence to: Yong Chan Lee, email: leeyc@yuhs.ac
}

Keywords: helicobacter pylori, CagA, SIRT3, HIF-1a, gastric cancer

Received: December 22, $2016 \quad$ Accepted: May 22, $2017 \quad$ Published: June 27, 2017

Copyright: Lee et al. This is an open-access article distributed under the terms of the Creative Commons Attribution License 3.0 (CC BY 3.0), which permits unrestricted use, distribution, and reproduction in any medium, provided the original author and source are credited.

\section{ABSTRACT}

Injection of the Helicobacter pylori cytotoxin-associated gene A (CagA) is closely associated with the development of chronic gastritis and gastric cancer. Individuals infected with $\boldsymbol{H}$. pylori possessing the CagA protein produce more reactive oxygen species (ROS) and show an increased risk of developing gastric cancer. Sirtuins (SIRTs) are nicotinamide adenine dinucleotide (NAD+)-dependent deacetylases and mitochondrial SIRT3 is known to be a tumor suppressor via its ability to suppress ROS and hypoxia inducible factor 1a (HIF-1a). However, it is unclear whether increased ROS production by $\boldsymbol{H}$. pylori is regulated by SIRT3 followed by HIF-1a regulation and whether intracellular CagA acts as a regulator thereof. In this study, we investigated correlations among SIRT3, ROS, and HIF-1a in $H$. pylori-infected gastric epithelial cells. We observed that SIRT3-deficient AGS cells induce HIF-1a protein stabilization and augmented transcriptional activity under hypoxic conditions. In $\mathrm{CagA}^{+} \boldsymbol{H}$. pylori infected cells, CagA protein localized to mitochondria where it subsequently suppressed SIRT3 proteins. CagA ${ }^{+} \boldsymbol{H}$. pylori infection also increased HIF-1a activity through the ROS production induced by the downregulated SIRT3 activity, which is similar to the hypoxic condition in gastric epithelial cells. In contrast, overexpression of SIRT3 inhibited the HIF-1a protein stabilization and attenuated the increase in HIF-1a transcriptional activity under hypoxic conditions. Moreover, $\mathrm{CagA}^{+} \boldsymbol{H}$. pylori attenuated HIF-1a stability and decreased transcriptional activity in SIRT3-overexpressing gastric epithelial cells. Taken together, these findings provide valuable insights into the potential role of SIRT3 in CagA ${ }^{+} H$. pylori-mediated gastric carcinogenesis and a possible target for cancer prevention via inhibition of HIF-1a.

\section{INTRODUCTION}

Previous studies have demonstrated that hypoxia is an important microenvironmental factor in promoting tumor progression [1]. Gastric cancers are exposed to hypoxia, as are many other solid tumors. Epidemiological studies have suggested that the development of gastric cancer may be attributed to hypoxia-induced reactive oxygen species (ROS) [2] and that ROS generated within the gastric mucosa are related to continuous exposure to H. pylori infection, ingested food, and cigarette smoking, etc. Accumulating data indicate that the $H$. pylori CagA 
protein, which is injected into gastric epithelial cells through T4SS, behaves as a bacterial oncoprotein [3]: CagA continuously dysregulates multiple oncogenic signaling pathways and promotes tumorigenesis [4]. Suzuki et al. found that ROS production in gastric epithelial cells was significantly enhanced by infection with CagA-positive $H$. pylori strains, resulting in an extensive accumulation of neutrophils [5], and was involved in tumor initiation, enhanced expression of oncogenes, and increased cell proliferation.

Increased ROS production may be involved in a variety of cellular changes, including changes in metabolism. Alterations in metabolism can help cancer cells survive various stresses, such as hypoxia and a limited supply of glucose. Some of the metabolic changes are facilitated by the transcription factor hypoxia inducible factor $1 \alpha(\mathrm{HIF}-1 \alpha)$ [6]. HIF-1 $\alpha$ activation is dependent on oxygen levels. Under normoxia, HIF-1 $\alpha$ is hydroxylated on proline residues by prolyl hydroxylase domain proteins (PHDs) and degraded by proteasomes. Under hypoxia, HIF- $1 \alpha$ is stabilized and translocated into the nucleus where it binds to the hypoxia-response element (HRE) in the promoters of target genes [1,7]. Mitochondrial electron transport chain-generated ROS can also stabilize HIF-1 $\alpha$, resulting in the transcription of genes involved in glucose transport and glycolytic enzymes, as well as promoting cell proliferation $[8,9]$.

Several members of the sirtuin family (SIRT1-7), the human homologues of the Sir2 gene in yeast, have been reported to play important roles in carcinogenesis [10]. Sirtuins are a family of nicotinamide adenine dinucleotide $\left(\mathrm{NAD}^{+}\right)$-dependent protein deacetylases [11]. Sirtuins regulate multiple cellular processes and physiological states, including oxidative stress, genomic stability, cell survival, development, metabolism, aging, and longevity $[12,13]$. Of the seven SIRT analogues, SIRT3, SIRT4, and SIRT5 are localized in the mitochondria [14]. Strikingly, SIRT3 deacetylates and activates several enzymes involved in cellular redox balance and defense against oxidative damage [15-18]. In addition, SIRT3 knock-out (KO) murine embryonic fibroblasts (MEFs) have been found to cause a shift towards glycolytic metabolism, exhibiting faster glucose uptake, lower levels of TCA intermediates, higher levels of lactate, and significantly faster proliferation, compared to wild-type MEFs [19, 20]. Recently, SIRT3 was reported to act as a mitochondrial localized tumor suppressor via its ability to inhibit mitochondrial ROS production. Loss of SIRT3 has been found to increase the production of ROS and to lead to HIF-1 $\alpha$ stabilization under hypoxic conditions. In contrast, SIRT3 overexpression has been shown to impede HIF-1 $\alpha$ stabilization in hypoxia and to inhibit tumorigenesis [19, $21,22]$. To our knowledge, the role of SIRT3 in H. pyloriinduced gastric carcinogenesis has not been investigated. In this study, we sought to investigate whether SIRT3 plays a role in the ROS production induced by the $H$. pylori oncoprotein CagA and whether increased ROS can affect HIF- $1 \alpha$ activation leading to $H$. pylori-mediated gastric carcinogenesis.

Herein, we show that loss of SIRT3 in gastric epithelial cells increases HIF-1 $\alpha$ protein stabilization and its transcriptional activity. Infection with $H$. pylori CagA induced downregulation of SIRT3 protein in mitochondria, stimulated ROS production, and elicited HIF-1 $\alpha$ stabilization with increased transcriptional activity, similar to that observed during hypoxia. Meanwhile, however, SIRT3-overexpressing gastric epithelial cells inhibited the stabilization of HIF-1 $\alpha$ protein in hypoxia and attenuated the observed increases in HIF-1 $\alpha$ transcriptional activity in hypoxia. Moreover, H. pylori CagA attenuated HIF$1 \alpha$ stability and its transcriptional activity in SIRT3overexpressing gastric epithelial cells. These findings suggest that $H$. pylori CagA induces HIF-1 $\alpha$ activity by downregulating SIRT3, followed by increases in ROS production, which provides a novel mechanism to explain the pathogenesis of $H$. pylori-mediated gastric carcinogenesis.

\section{RESULTS}

\section{SIRT3 knockdown increases proliferation of gastric epithelial cells and HIF-1 $\alpha$ activity through ROS generation}

Loss of SIRT3 has been shown to increase mitochondrial ROS production and HIF-1 $\alpha$ activity under hypoxic conditions [22]. We sought to investigate whether SIRT3 knockdown plays a role in the progression of gastric cancer using established gastric epithelial cell lines. We knocked down SIRT3 in the gastric epithelial cells with short-hairpin (sh)RNA and explored whether SIRT3 knockdown affected the hypoxic activation of HIF-1 $\alpha$. We found that SIRT3 knockdown in gastric epithelial cells under hypoxic conditions resulted in increased expression of HIF-1 $\alpha$ protein, compared to the scrambled control (Figure 1A). We next examined whether there is a concomitant increase in HIF-1 $\alpha$ transcriptional activity using the reporter construct with hypoxia responsive element (HRE) [22]. Under hypoxic conditions, there was a 40-fold increase in HREluciferase activity in the scrambled control, compared with normoxic conditions, whereas the SIRT3 knockdown cells demonstrated a 70-fold increase in luciferase activity under the same conditions (Figure 1B). Consistent with this, the expression of HIF-1 $\alpha$ target genes, such as $V e g f-a, P d k 1$, and Ldha, were significantly elevated, compared to the control, during hypoxia, and the loss of SIRT3 further increased expression of these HIF-1 $\alpha$ target genes (Figure 1C). Hypoxic conditions have been reported to increase ROS production, and these higher ROS levels are sufficient to stabilize and activate HIF$1 \alpha[22,23]$. As expected, we also observed increased 
ROS levels in SIRT3 knockdown AGS cells, compared with the control, in hypoxic conditions (Figure 1D). To determine whether the source of the increased ROS production in the absence of SIRT3 was complex I or III of mitochondria, we measured HIF- $1 \alpha$ activity by luciferase assay in the presence or absence of selective inhibitors of mitochondrial complex I or complex III. DPI has been used to inhibit ROS production mediated by plasma membrane $\mathrm{NAD}(\mathrm{P}) \mathrm{H}$ oxidase $[24,25]$ and has also been reported to inhibit the production of superoxide and $\mathrm{H}_{2} \mathrm{O}_{2}$ by mitochondria through inhibiting NADH-ubiquinone oxidoreductase (complex I) [26, 27]. Myxothiazol binds at the quinol oxidation (Qo) site of the bcl complex (complex III) to block electron transfer, and impairs ROS production [28]. We found that addition of inhibitors attenuated the increase in HRE-luciferase activity in the SIRT3 knockdown cells cultured under hypoxic conditions (Figure 1E), thereby demonstrating that the increase in HIF-1 $\alpha$ activity with hypoxic conditions is due to ROS generated by the mitochondrial electron transport chain. To demonstrate the role of SIRT3 in the progression of tumors, we injected control and SIRT3 knockdown AGS cells into the flanks of nude mice, and tumor growth was measured after the subcutaneous injection. We found that tumor volume derived from SIRT3 knockdown cells was significantly increased, compared with control cells
A

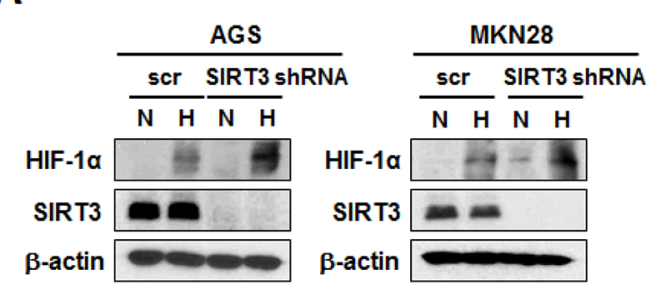

D

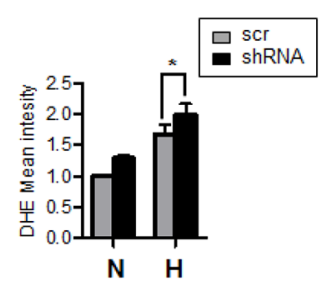

G

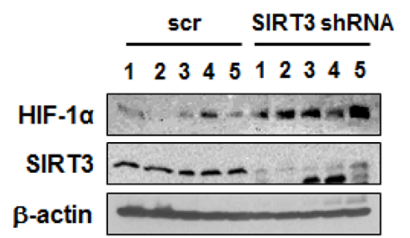

H
B

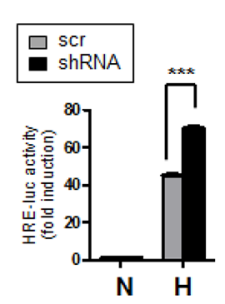

E

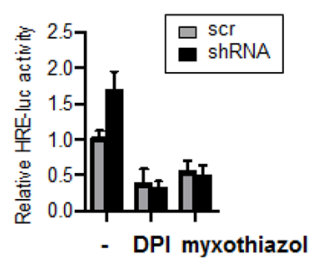

$\mathbf{F}$
C

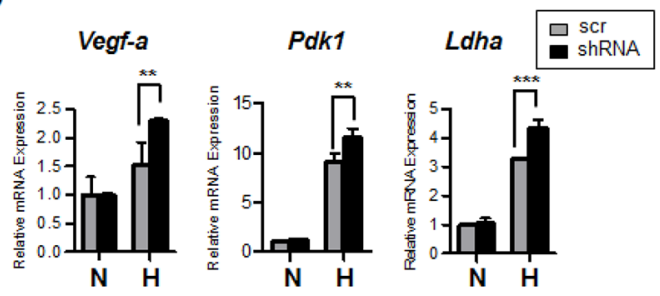

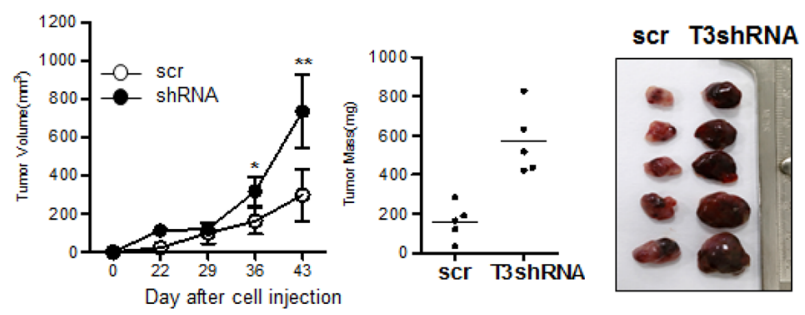

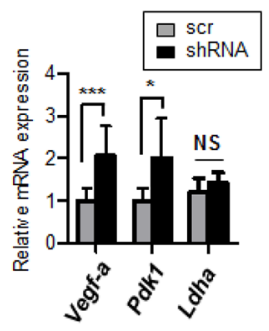

I

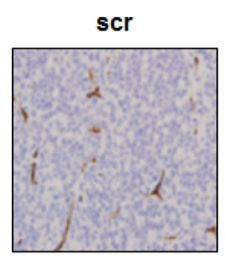

SIRT3 shRNA

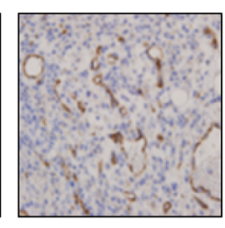

Figure 1: SIRT3 knockdown in gastric epithelial cells increases HIF-1 $\alpha$ activity and induces tumor growth. (A) SIRT3 and HIF-1 $\alpha$ protein levels were detected by immunoblotting extracts from AGS and MKN28 cells stably expressing a scrambled control shRNA (scr) or SIRT3 shRNA at normoxic $\left(\mathrm{N}, 21 \% \mathrm{O}_{2}\right)$ or hypoxic $\left(\mathrm{H}, 1 \% \mathrm{O}_{2}\right)$ conditions for $12 \mathrm{~h}$. (B) SIRT3 stable knockdown cell lines (shRNA) or a scrambled control vector (scr) line were transfected with HRE-luciferase for $24 \mathrm{~h}$ and incubated in normoxic or hypoxic conditions for $16 \mathrm{~h}$, after which luciferase reporter activity was measured. (C) RNA was isolated from AGS cells stably expressing SIRT3 shRNA or a scrambled control vector (scr) cultured in normoxic or hypoxic conditions for $16 \mathrm{~h}$. The expression of HIF-1 $\alpha$ target genes in response to hypoxia was measured by real-time PCR using specific primers for Vegf-a, Pdk-1, and Ldha. (D) ROS levels were measured by FACS analysis for AGS cells with SIRT3 knockdown or a scrambled control (scr) cultured in normoxic or hypoxic conditions for $12 \mathrm{~h}$. (E) Scrambled or SIRT3 shRNA stable cell lines were transfected with HRE-luciferase for $24 \mathrm{~h}$, treated with inhibitors DPI or myxothiazol for $1 \mathrm{~h}$, and then, incubated in normoxic or hypoxic conditions for $16 \mathrm{~h}$. Firefly luciferase reporter activity was measured and normalized to Renilla luciferase activity. (F) AGS cells expressing control or SIRT3 shRNA were subcutaneously injected into the flanks of nude mice $(n=5)$. Xenograft tumor volumes were monitored weekly and growth curves were plotted (left panel). Xenograft tumors were excised and weighed at the end of the experiment (middle panel). Pictures of dissected tumors are shown in the right panel. Each bar indicates the mean \pm S.E. $\left(\mathrm{n}=5 ;{ }^{*} \mathrm{p}<0.05 ; * * \mathrm{p}<0.01 ; * * * \mathrm{p}<0.001\right)$. (G) Tumor samples from nude mice injected with control, and SIRT3 shRNA AGS cells were lysed and immunoblotted with anti-HIF-1 $\alpha$ and SIRT3. (H) Vegf- $a$ and Pdk1 expression levels were measured by real-time PCR with isolated total RNA from tumor samples. (I) Tumor samples were collected, and immunohistochemical staining was performed with antiCD31 antibody. Data are represented as mean $\pm \mathrm{SD}(\mathrm{n}=3) .{ }^{*} \mathrm{p}<0.05 ; * * \mathrm{p}<0.01 ; * * * \mathrm{p}<0.001$ 
(Figure 1F). In addition, HIF-1 $\alpha$ protein levels and the expression of HIF-1 $\alpha$ target genes were analyzed, and the expression of $V e f g-a$ and $P d k 1$ were significantly increased in SIRT3-deficient tumor tissues, compared with the controls, as was the degree of angiogenic activity, as determined by immunostaining for the endothelial cellspecific marker CD31 (Figure 1G-1I). Taken together, these results indicate that SIRT3 loss is linked to tumorigenesis mediated via ROS-induced HIF-1 $\alpha$ activity, leading to enhanced angiogenesis and glycolytic pathway metabolism.

\section{Infection with $\boldsymbol{H}$. pylori CagA increases HIF-1a activity and expression of HIF-1 $\alpha$ target genes}

To examine HIF-1 $\alpha$ protein expression in relation to the oncoprotein CagA secreted by H. pylori, extracts from cells infected with $H$. pylori strains were immunoblotted using HIF-1 $\alpha$ antibody. In this experiment, we used four strains of $H$. pylori (two CagA-negative and two CagApositive strains) and confirmed the expression of CagA protein in $\mathrm{CagA}^{+}$strains (60190 and $\triangle v a c A$ 60190) (Figure 2A). Surprisingly, stronger expression of HIF-1 $\alpha$ protein was observed in $\mathrm{CagA}^{+} H$. pylori strains than in the $\mathrm{CagA}^{-}$strains (Figure 2B, Supplementary Figure 1). Immunoblotting of cytosolic and nuclear fractions showed that infection with $\mathrm{CagA}^{+}$H. pylori induced greater HIF$1 \alpha$ nuclear translocation than $\mathrm{CagA}^{-} H$. pylori (Figure $2 \mathrm{C}$ ). In line with this finding, the trancriptional activity of HIF$1 \alpha$ was increased on infection with $\mathrm{CagA}^{+} H$. pylori strains in accordance with $H$. pylori CagA expression status (Figure 2D). In addition, expression levels of the HIF-1 $\alpha$ target genes Vegf-a, Pdk1, and Ldha were higher in $\mathrm{CagA}^{+}$ H. pylori, compared to $\mathrm{CagA}^{-} H$. pylori, without affecting Hif- $1 \alpha$ mRNA levels (Figure 2E). These results suggest that infection with $\mathrm{CagA}^{+} H$. pylori stimulates HIF-1 $\alpha$ in gastric cells similar to that observed in the hypoxic response.

\section{H. pylori CagA infection downregulates SIRT3 activity in mitochondria via proteasomal degradation}

To determine whether there were any changes in SIRT3 expression following infection with various $H$. pylori strains, we examined whole cell SIRT3 protein levels in $H$. pylori-infected cells. Total SIRT3 protein levels were not altered in $H$. pylori-infected cells (Figure 3A). We decided to measure SIRT3 protein levels and their enzymatic activity in the mitochondria by preparing mitochondrial extracts from $H$. pylori-infected cells. Interestingly, the protein levels and enzymatic activity of SIRT3 in mitochondria
A

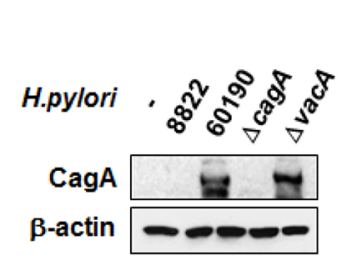

D

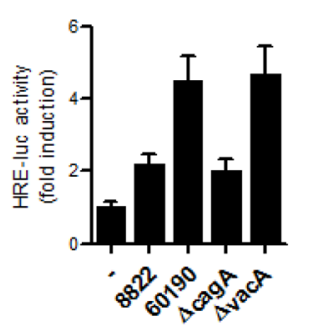

B

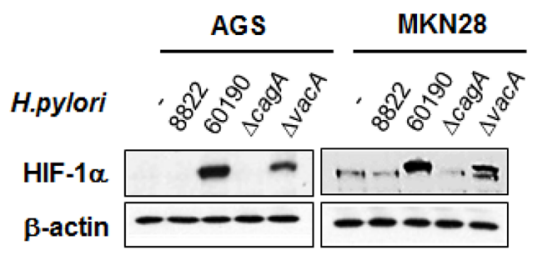

E

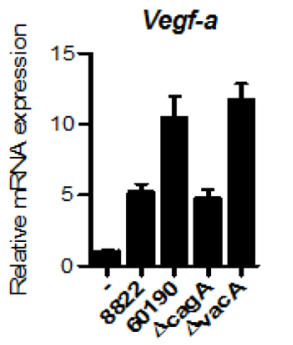

C
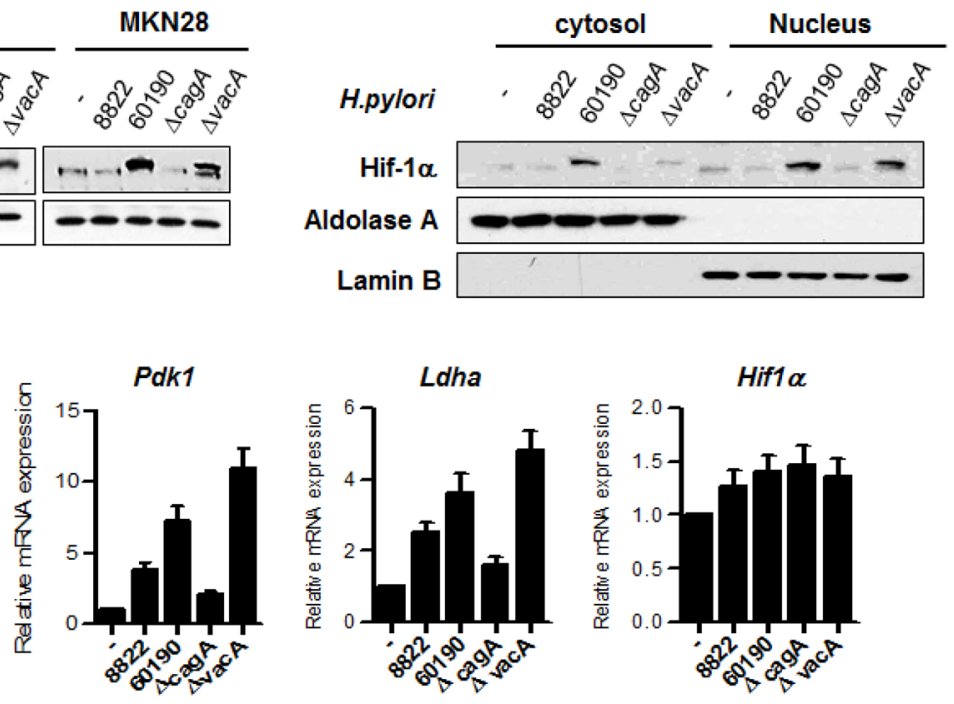
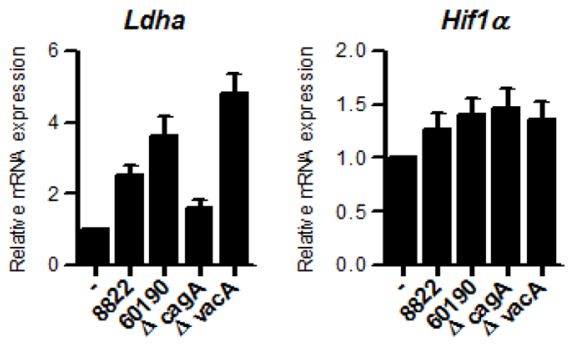

Figure 2: $\boldsymbol{H}$. pylori CagA increases HIF-1 $\alpha$ activity and induces expression of HIF-1 $\alpha$ target genes. (A) AGS cells were infected with $H$. pylori strains for $6 \mathrm{~h}$ and the CagA protein level was analyzed by immunoblotting. (B) Lysates from AGS and MKN28 cells infected with $H$. pylori strains were immunoblotted with anti-HIF- $1 \alpha$, and then, the membrane was stripped and analyzed with anti- $\beta$-actin to standardize gel loading. (C) MKN28 cells were infected with $H$. pylori strains for $6 \mathrm{~h}$, and then, cytoplasmic and nuclear fractions were separated. The nuclear proteins were analyzed by immunoblotting with anti-HIF-1 $\alpha$. To verify complete separation of the cytosolic and nuclear fractions, cytosolic and nuclear extracts were immunoblotted for aldolase A and lamin B. (D) MKN28 cells were co-transfected with HRE-Luc together with TK-renilla for $24 \mathrm{~h}$ and then infected with $H$. pylori strains for $12 \mathrm{~h}$. Firefly luciferase activity was measured and normalized to Renilla luciferase activity. (E) MKN28 cells were infected with $H$. pylori for $12 \mathrm{~h}$, and the fold change in HIF-1 $\alpha$ target gene levels was measured by real-time PCR using specific primers for Vegf- $a, P d k-1$, Ldha, and Hif-1 $\alpha$. Data are represented as mean \pm SD ( $\mathrm{n}=3$ ). 
were significantly reduced upon infection with $\mathrm{CagA} \mathrm{A}^{+}$ H. pylori, compared with $\mathrm{CagA}^{-} H$. pylori (Figure 3B and $3 \mathrm{C}$ ). The low level of SIRT3 protein in mitochondria of $\mathrm{CagA}^{+} H$. pylori-infected cells was intriguing. Some proteins involved in bioenergetic metabolism localized in the mitochondria ( $\mathrm{p} 53, \mathrm{p} 70, \mathrm{ODC}, \mathrm{SOD} 1$, etc.) are known to be degraded by an ubiquitin-independent process in response to oxidative stress $[29,30]$. We investigated whether proteasomal degradation could contribute to the low level of mitochondrial SIRT3 protein in $\mathrm{CagA}^{+} H$. pylori-infected cells. We pretreated cells with the specific proteasome inhibitor MG132 prior to $H$. pylori infection and found that MG132 was able to block SIRT3 protein degradation in cells (Figure 3D).

\section{Increased ROS production induced by $H$. pylori CagA infection regulates HIF-1 $\alpha$ stability}

A fraction of expressed CagA protein has been reported to localize to mitochondria and produce significant amounts of ROS in infected cells. The mechanism by which CagA induces ROS production in gastric epithelial cells is not known $[2,31]$. We thus examined whether H. pylori CagA protein localizes to mitochondria and increases ROS production. Immunoblotting after subcellular fractionation revealed CagA protein in both cytoplasmic and mitochondrial fractions (Figure 4A, left panel). In immunofluorescence analysis, with the CagA protein stained green and mitochondria stained red, yellow showed the colocalization of CagA and mitochondria in cells, consistent with the immunoblotting findings (Figure 4A, right panel). Next, we measured ROS levels using immunofluorescence assays and FACS analysis in AGS cells infected with the relevant $H$. pylori strains. Interestingly, we observed an increase of ROS in $\mathrm{CagA}^{+}$ H. pylori strains (Figure 4B), suggesting that CagA protein localized to the mitochondria has the potential to produce ROS. To determine whether the activation of HIF-1 $\alpha$ is due to ROS, we treated AGS cells with antioxidants and determined the extent of HIF- $1 \alpha$ activation. GSH precursor N-acetyl-cysteine (NAC), catalase, allopurinol, and DESF were added to cells before $H$. pylori infection. These antioxidants failed to downregulate HIF-1 $\alpha$ expression (Figure 4C), implying that these antioxidants did not effectively scavenge the secreted extracellular oxidant in these cells. In order to determine the cellular source of ROS, DPI (complex I inhibitor) and myxothiazol (complex III inhibitor) were used to pretreat the cells before infection with $H$. pylori. Both inhibitors downregulated the stability and transcriptional activity of HIF- $1 \alpha$, indicating that the increased HIF- $1 \alpha$ activity in $\mathrm{CagA}^{+} H$. pylori-infected AGS cells was mainly due to ROS produced by mitochondrial complex I and III (Figure 4D).
A

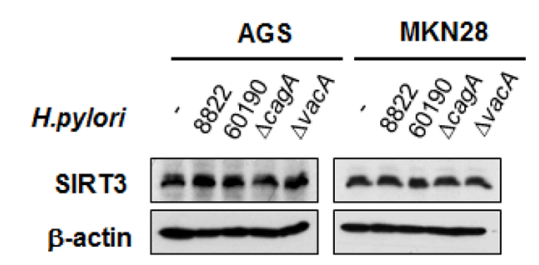

C
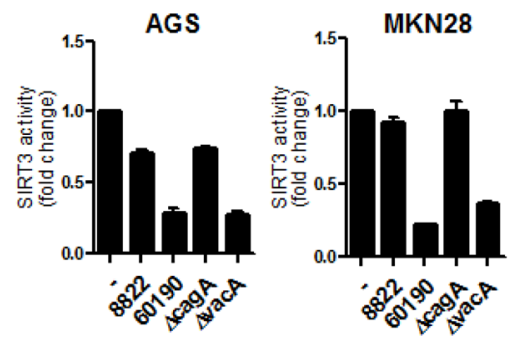

B
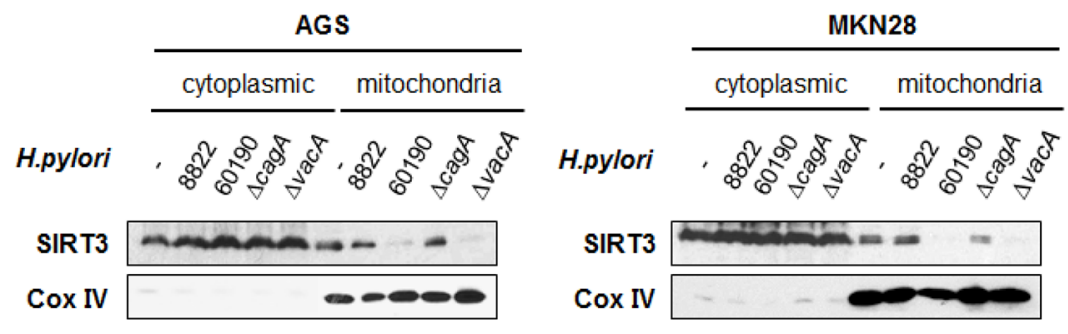

D

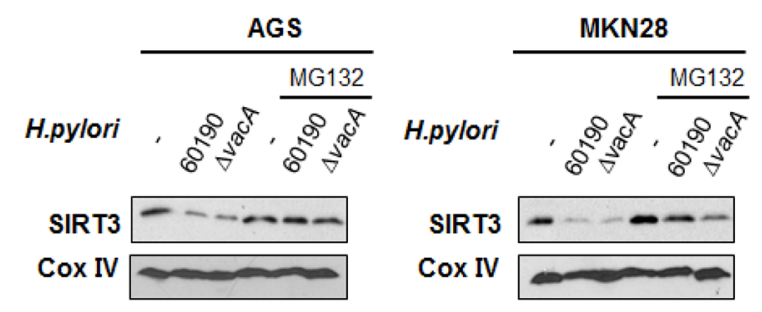

Figure 3: $H$. pylori CagA downregulates SIRT3 activity in the mitochondria via proteasomal degradation. (A) SIRT3 protein levels were detected by immunoblotting from AGS and MKN28 cells infected with H. pylori for 6 h. (B) Cytoplasmic (Cyt) and mitochondrial (Mito) proteins were fractionated from $H$. pylori-infected AGS and MKN28 cells after 6 h and analyzed by immunoblotting. Cox IV, a known mitochodrial protein, was detected as a control. (C) Relative activity of SIRT3 was measured using a fluorimetric method from the mitochondrial extracts of AGS and MKN28 cells infected with $H$. pylori for $6 \mathrm{~h}$. Values represent fold changes relative to the control. (D) AGS or MKN28 cells were pretreated with MG132 $(10 \mu \mathrm{M})$ for $1 \mathrm{~h}$ prior to infection with CagA $\mathrm{A}^{+}$. pylori strains. The mitochondrial fraction was subjected to immunoblot analysis using anti-SIRT3 antibody. As a loding control, blots were stripped and reprobed with anti-Cox IV. Data are represented as mean $\pm \mathrm{SD}(\mathrm{n}=3)$. 


\section{$\mathrm{CagA}^{+} H$. pylori-induced HIF-1 $\alpha$ stabilization is regulated by post-translational modification}

We next tested the hypothesis that CagA-induced HIF- $1 \alpha$ stabilization may be due to post-translational modification, because there were no significant differences in HIF- $1 \alpha$ mRNA levels in $H$. pylori-infected cells. We assessed HIF- $1 \alpha$ stability by treating cells with MG-132 to prevent hydroxylated HIF- $1 \alpha$ from being degraded. Although $\mathrm{CagA}^{+} H$. pylori infection stabilized more HIF-1 $\alpha$ during MG-132 treatment, cells had significantly less hydroxylated HIF-1 $\alpha$, indicating that PHD activity was lower in $\mathrm{CagA}^{+} H$. pylori-infected cells, compared to CagA- cells (Figure 5A). Of all the PHDs, PHD2 and PHD3 were detected in both gastric epithelial cell lines (Figure 5B), and PHD2 is known to be the primary mediator of hydroxylation [32]. Since $\mathrm{CagA}^{+} H$. pylori infection influences HIF-1 $\alpha$ stability through modulation of PHD activity, pretreatment with the potent PHD inhibitor DMOG in CagA- H. pylori-infected cells, as expected, showed relatively restored HIF- $1 \alpha$ stabilization (Figure 5C). These results suggested that increased HIF$1 \alpha$ expression contributes to reduced PHD activity in $\mathrm{CagA}^{+} H$. pylori-infected cells (Figure 5D). $\mathrm{CagA}^{+} H$. pylori activates HIF- $1 \alpha$ through ROS-mediated alteration of PHD function, thereby altering hydroxylation and subsequent proteasomal degradation of HIF- $1 \alpha$.

\section{SIRT3 gain of function inhibits HIF-1 $\alpha$ activity and expression of HIF-1 $\alpha$ target genes}

We generated AGS and MKN28 cells stably expressing doxycycline-inducible SIRT3 and confirmed SIRT3 overexpression after the addition of doxycycline by immunoblotting (Figure 6A). By FACS analysis, SIRT3-overexpressing cells showed decreased ROS levels, compared to control cells, in the hypoxic condition (Figure 6B). When induced by doxycycline treatment, cells overexpressing SIRT3 clearly had both reduced HIF- $1 \alpha$ protein stability and HIF- $1 \alpha$ transcriptional activity under hypoxia, compared with the control (Figure 6C and 6D). Expression of the HIF$1 \alpha$ responsive target genes Vegf- $a, P d k l$, and Ldha was attenuated, corresponding to reduced HIF- $1 \alpha$ activity, in SIRT3-overexpressing cells (Figure 6E). To examine whether SIRT3 has a role in inhibiting tumor growth in vivo, we injected SIRT3-overexpressing AGS cells into the flanks of nude mice. Tumor weights and volumes derived from SIRT3-overexpressing cells were smaller than those from the un-induced cells (Figure 6F).
A

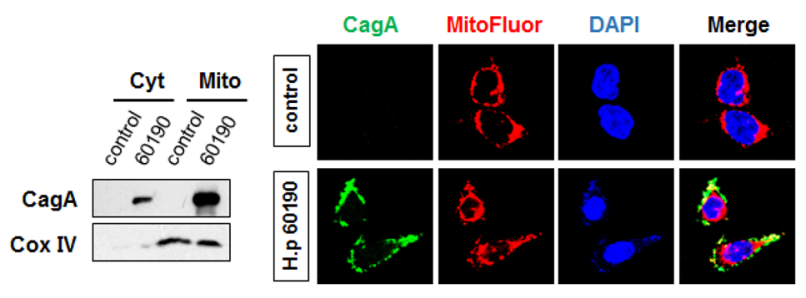

C

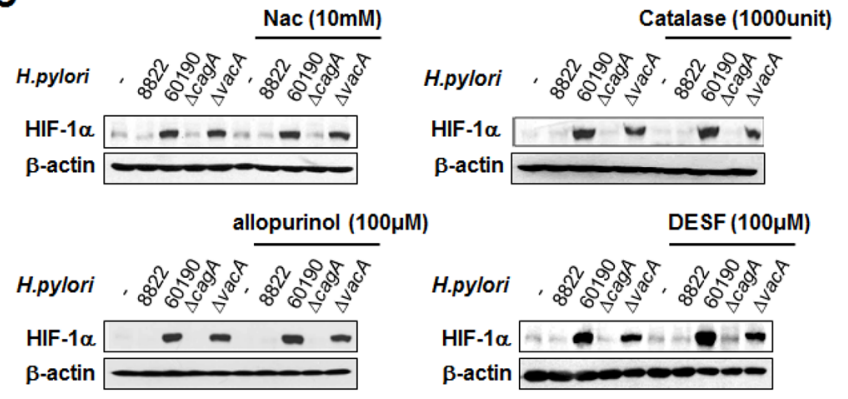

B

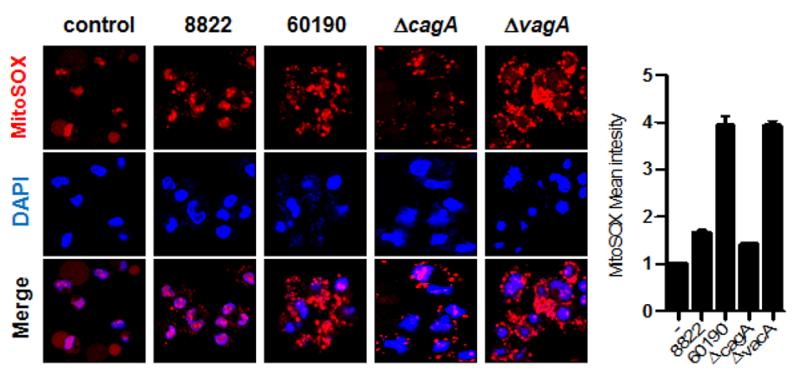

D

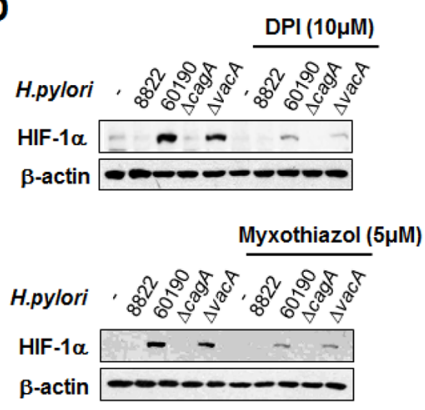

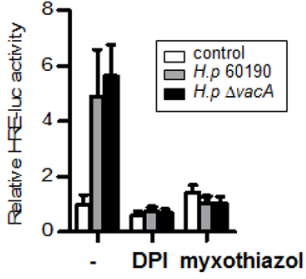

DPI myxothiazol

Figure 4: H. pylori CagA protein localizes to mitochondria and is involved in ROS production. (A) Cytoplasmic (Cyt) and mitochondrial (Mito) proteins were fractionated from H. pylori-infected AGS cells and analyzed by immunoblotting (left panel) and immunofluorescence (right panel) with anti-CagA antibody. In immunofluorescence microscopy, CagA was stained in green, mitochondria in red, and DNA in blue with 4',6-diamidino-2-phenylindole (magnification x100). (B) AGS cells were infected with $H$. pylori for 6 h and stained with Mitosox, followed by immunofluorescence (left panel) and FACS analysis (right panel). (C) AGS cells were pretreated with antioxidants (NAC, catalase, allopurinol, and DESF) prior to H. pylori infection and extracts were immunoblotted with HIF-1 $\alpha$ antibody. (D) AGS cells were pretreated with DPI or myxothiazol and then the extracts were immunoblotted (left panel). AGS cell were co-transfected with HRE-Luc and TK-renilla constructs for $24 \mathrm{~h}$ and treated with the inhibitors DPI or myxothiazol for $1 \mathrm{~h}$. Cells were then infected with $\mathrm{CagA}^{+}$H. pylori strains for $6 \mathrm{~h}$, and luciferase reporter activity was measured. Data are represented as mean $\pm \mathrm{SD}(\mathrm{n}=3)$. 
$\mathrm{CagA}^{+} H$. pylori infection showed increased HIF-1 $\alpha$ stabilization and enhanced activity. We sought to determine the effect of SIRT3 overexpression on $\mathrm{CagA}^{+} H$. pyloriinduced HIF-1 $\alpha$ stabilization. We found that the level of HIF-1 $\alpha$ protein was reduced in SIRT3-overexpressing cells infected with $\mathrm{CagA}^{+}$H. pylori (Figure 6G). ROS levels, HIF- $1 \alpha$ transcriptional activity, and expression of HIF- $1 \alpha$ target genes were also downregulated in $\mathrm{CagA}^{+} H$. pyloriinfected SIRT3-overexpressing cells (Figure 6H-6J), indicating that SIRT3 is an effector molecule responsible for negative regulation of ROS, HIF-1 $\alpha$, and tumor growth induced by $H$. pylori CagA. All of these findings suggest a novel mechanism whereby downregulation of SIRT3 in $H$. pylori $\mathrm{CagA}^{+}$infected gastric cells induces ROS, HIF- $1 \alpha$ activity, and tumor growth (Figure 7).

\section{DISCUSSION}

This study was designed to answer the question whether the tumor suppressor SIRT3 protein influences
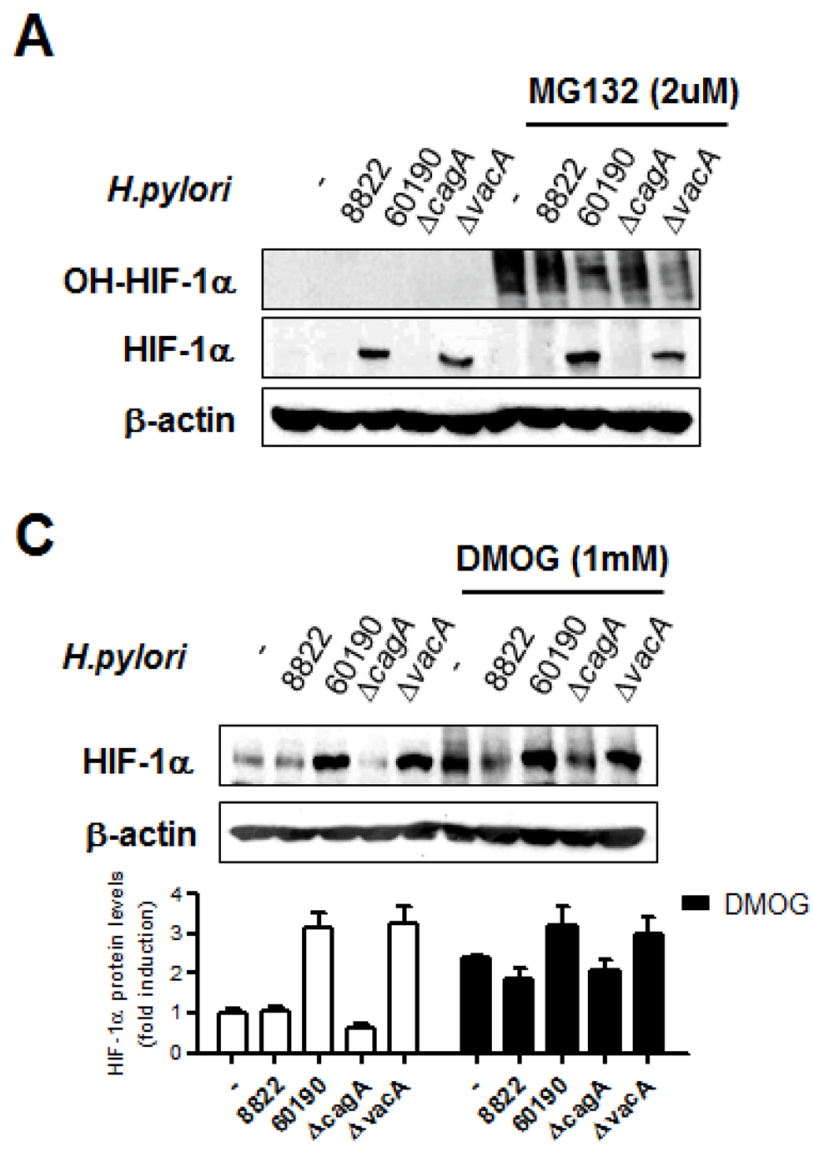

ROS production and HIF-1 $\alpha$ activity in $H$. pyloriinfected gastric cancer cells. Using the established SIRT3 knockdown or SIRT3 overexpressing gastric epithelial cells to investigate the role of SIRT3, we confirmed results from previous studies that suggested that SIRT3 functions as a tumor suppressor due to the suppression of ROSmediated HIF-1 $\alpha$ activation [22].

Next, we examined the role of SIRT3 in regulating $\mathrm{ROS} / \mathrm{HIF}-1 \alpha$ in $H$. pylori-infected gastric cells in vitro. In this study, $H$. pylori infection showed higher ROS production and HIF-1 $\alpha$ activation in an oncoprotein CagA-dependent manner. The increased ROS triggered by $\mathrm{CagA}^{+} H$. pylori might be attributed to the localization of CagA to the mitochondria (Figure 4A and 4B), with subsequent deregulation of the mitochondrial electron transport chain and production of superoxide $[2,31]$. Vacuolating cytotoxin (VacA) protein, another known virulence factor of $H$. pylori, via pinocytosis and intracellular trafficking, induces vacuolation and epithelial cell apoptosis and this effect has been attributed

B

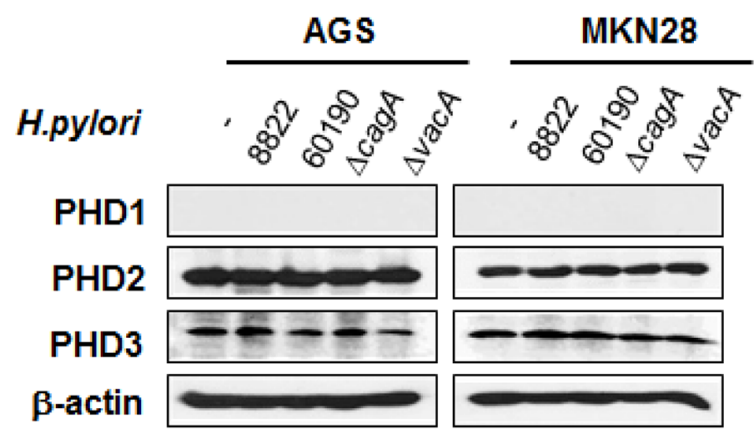

D

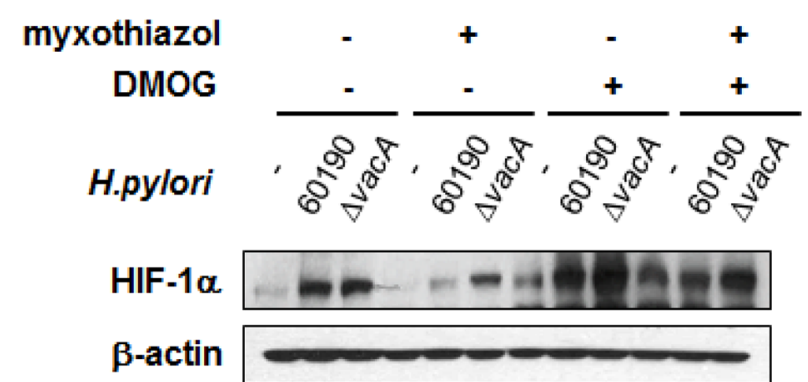

Figure 5: $\mathrm{CagA}^{+} \boldsymbol{H}$. pylori-induced HIF-1 $\alpha$ stabilization is regulated by prolyl hydroxylase (PHD) activity. (A) AGS cells were pretreated with or without $10 \mu \mathrm{M} \mathrm{MG}-132$ for $1 \mathrm{~h}$ and infected with $H$. pylori for $6 \mathrm{~h}$. Cell lysates were immunoblotted with antibodies specific for hydroxylated HIF-1 $\alpha$ (OH-HIF-1 $\alpha)$ and total HIF-1 $\alpha$. (B) After infection with H. pylori for 6 h, immunoblotting was performed using the indicated antibodies. (C) AGS cells were pretreated with or without $1 \mathrm{mM}$ DMOG for $2 \mathrm{~h}$ and infected with $H$. pylori for $6 \mathrm{~h}$. Cell lysates were immunoblotted with anti-HIF-1 $\alpha$ antibody. Densitometric ratios between HIF-1 $\alpha$ and $\beta$-actin immunoblotting are shown at the bottom. (D) After treatment with the indicated inhibitors prior to CagA ${ }^{+} H$. pylori infection, HIF-1 $\alpha$ protein levels were detected by immunoblotting. Data are represented as mean $\pm \mathrm{SD}(\mathrm{n}=3)$. 
to interactions with mitochondria [33-34]. It has been understood that VacA is capable of inducing an influx of $\mathrm{Ca}^{2+}$, resulting in the leakage of mitochondrial cytochrome $c$ and the generation of reactive oxygen intermediates (ROI) [35-41]. We, however, observed that CagA induced significantly greater ROS production than VacA. This suggests that ROS-induced HIF-1 activation in $H$. pylori infected gastric cell lines is influenced by CagA protein more than VacA.

Interestingly, we found that antioxidants, such as NAC, catalase, allopurinol, etc., were unable to efficiently scavenge the secreted ROS in $\mathrm{CagA}^{+} H$. pylori-infected gastric cells. Other reports have demonstrated that the amounts of catalase and superoxide dismutase (SOD) released by $H$. pylori are likely insufficient to clear excess extracellular oxidants [42] and that regulating the source of ROS generation is likely to be a more effective means of reducing ROS production. Therefore, we propose that impairment in the mitochondrial electron transport complex I or III by H. pylori CagA translocation results in increased ROS production and gives rise to a positive loop between ROS and HIF- $1 \alpha$.

It was previously reported that HIF-1 $\alpha$ has a carcinogenic role in gastric cancer (43-44). Griffiths et al. investigated HIF-1 $\alpha$ expression during carcinogenesis in $H$. pylori infection and showed that HIF-1 $\alpha$ was not expressed in the normal gastric mucosa, while expression increased in density and intensity with sequential progression from $H$. pylori-infected mucosa to gastric cancer [43]. Another study observed increased VEGF expression, HIF-1 $\alpha$ target gene expression, and new microvessel formation in $H$. pylori-infected gastric mucosa [44]. Here, we studied the possible linkage between oncogenic CagA protein and HIF-1 $\alpha$ expression. In $H$. pylori-infected gastric epithelial cells, $\mathrm{CagA}^{+} H$. pylori increased not only HIF-1 $\alpha$ protein levels, but also HIF- $1 \alpha$ activity and the expression of HIF- $1 \alpha$-target genes, including Vegf, Ldha, and $P d k 1$, even under normoxic
A

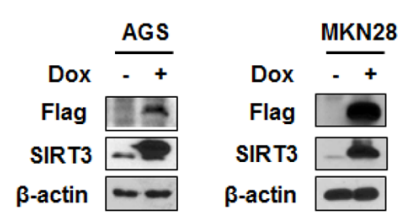

B

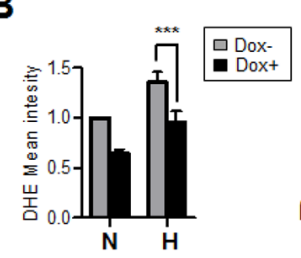

C

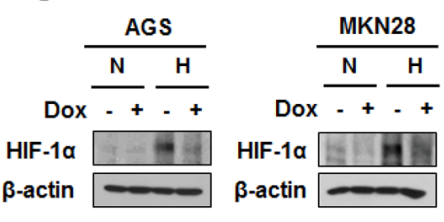

D

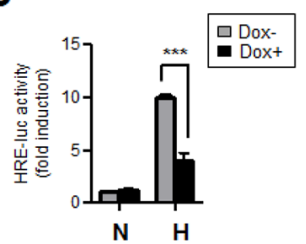

E
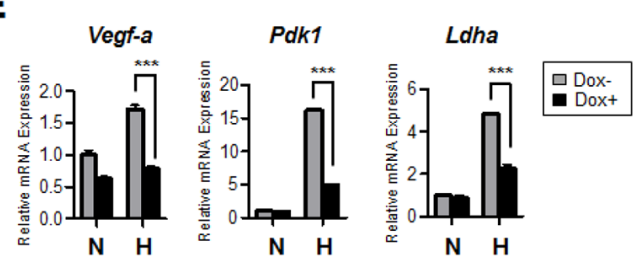

$F$
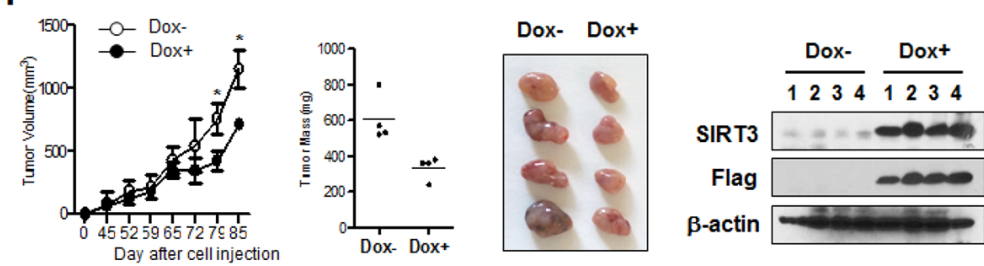

G

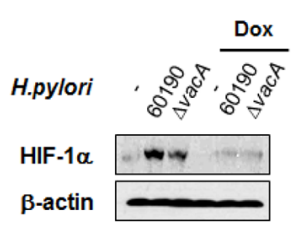

$\mathrm{H}$

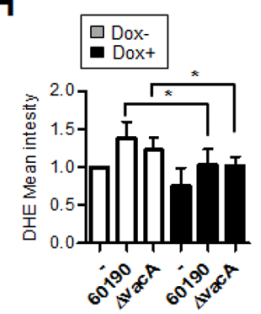

I

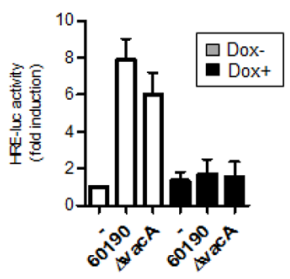

J

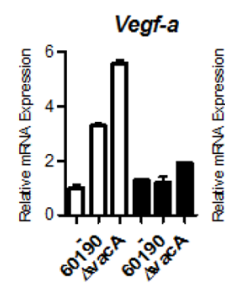

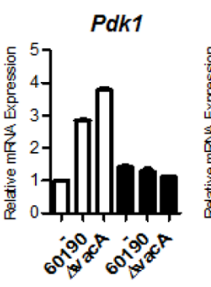

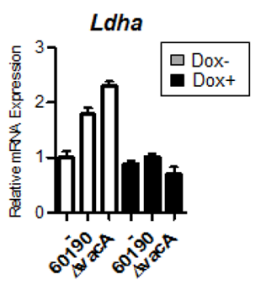

Figure 6: SIRT3 gain of function inhibits HIF-1 $\alpha$ activity and expression of HIF-1 $\alpha$ target genes. (A) After generating derivatives of the gastric cancer cells AGS and MKN28 stably expressing doxycycline-inducible SIRT3, doxycycline $(2 \mu \mathrm{M})$ was added to the cells for $48 \mathrm{~h}$. Immunoblotting was then performed to detect SIRT3 overexpression using anti-Flag antibody. (B) Cells with inducible overexpression of SIRT3 were incubated in the presence or absence of Dox under normoxic $\left(\mathrm{N}, 21 \% \mathrm{O}_{2}\right)$ or hypoxic $\left(\mathrm{H}, 1 \% \mathrm{O}_{2}\right)$ conditions for $12 \mathrm{~h}$, and then FACS analysis was performed to measure the amount of ROS. (C) For the immunoblotting assay, cells with inducible overexpression of SIRT3 in the presence or absence of Dox were incubated in normoxic or hypoxic conditions for $12 \mathrm{~h}$. For the luciferase reporter assay (D) and for real time PCR (E) similar cells were incubated in normoxic or hypoxic conditions for $16 \mathrm{~h}$. (F) Tumor volume and mass (left two panels) of SIRT3-overexpressing cells were measured. Pictures of tumors (third panel) are shown, and confirmation of SIRT3 overexpression by immunoblotting using lysates of the tumor samples (fourth panel). Each bar indicates the mean $\pm \mathrm{S}$.E. ( $\mathrm{n}=4$; ${ }^{*} \mathrm{p}<0.05$ ). (G) After overexpressing SIRT3 in AGS cells with dox for 48 h, cells were infected with CagA H. pylori strains for 6 h. The HIF-1 $\alpha$ protein level was detected by immunoblot analysis. (H) ROS levels were measured by FACS analysis. (I) HIF-1 $\alpha$ transcriptional activity was measured by luciferase assay. (J) The expression levels of HIF-1 $\alpha$ target genes (Vegf-1a, Pdkl, and Ldha) were measured by real-time PCR. Data are represented as mean $\pm \mathrm{SD}(\mathrm{n}=3) .{ }^{*} \mathrm{p}<0.05, * * \mathrm{p}<0.01, * * * \mathrm{p}<0.001$. 
conditions in vitro. We strongly believe that $H$. pylori oncogenic CagA induces ROS production to stabilize HIF$1 \alpha$ and influences gastric cancer initiation and progression.

We also examined the relationship between SIRT3 activity and ROS-induced HIF- $1 \alpha$ activation in $H$. pylori infection. Surprisingly, we observed lower levels of SIRT3 protein and activity in the mitochondria extracts of the $\mathrm{CagA}^{+} H$. pylori infected cells. We attempted to identify a possible mechanism for the attenuation of SIRT3 in the mitochondria of $\mathrm{CagA}^{+} H$. pylori-infected cells. Some studies have demonstrated that exposure of mammalian cells in culture to moderate oxidative stress significantly increases the degradation of intracellular proteins [45, 46]. The proteasome machinery appears to be upregulated in response to oxidative stress and to be responsible for the degradation of oxidized proteins in mammalian cells [45, 47]. We confirmed that SIRT3 proteins are restored by blocking proteasomal activation, suggesting that oxidative stress by $H$. pylori infection can degrade SIRT3 protein. This is, however, still unclear, and additional study is required to understand how the $H$. pylori oncogenic CagA induces the degradation of mitochondrial SIRT3. We also

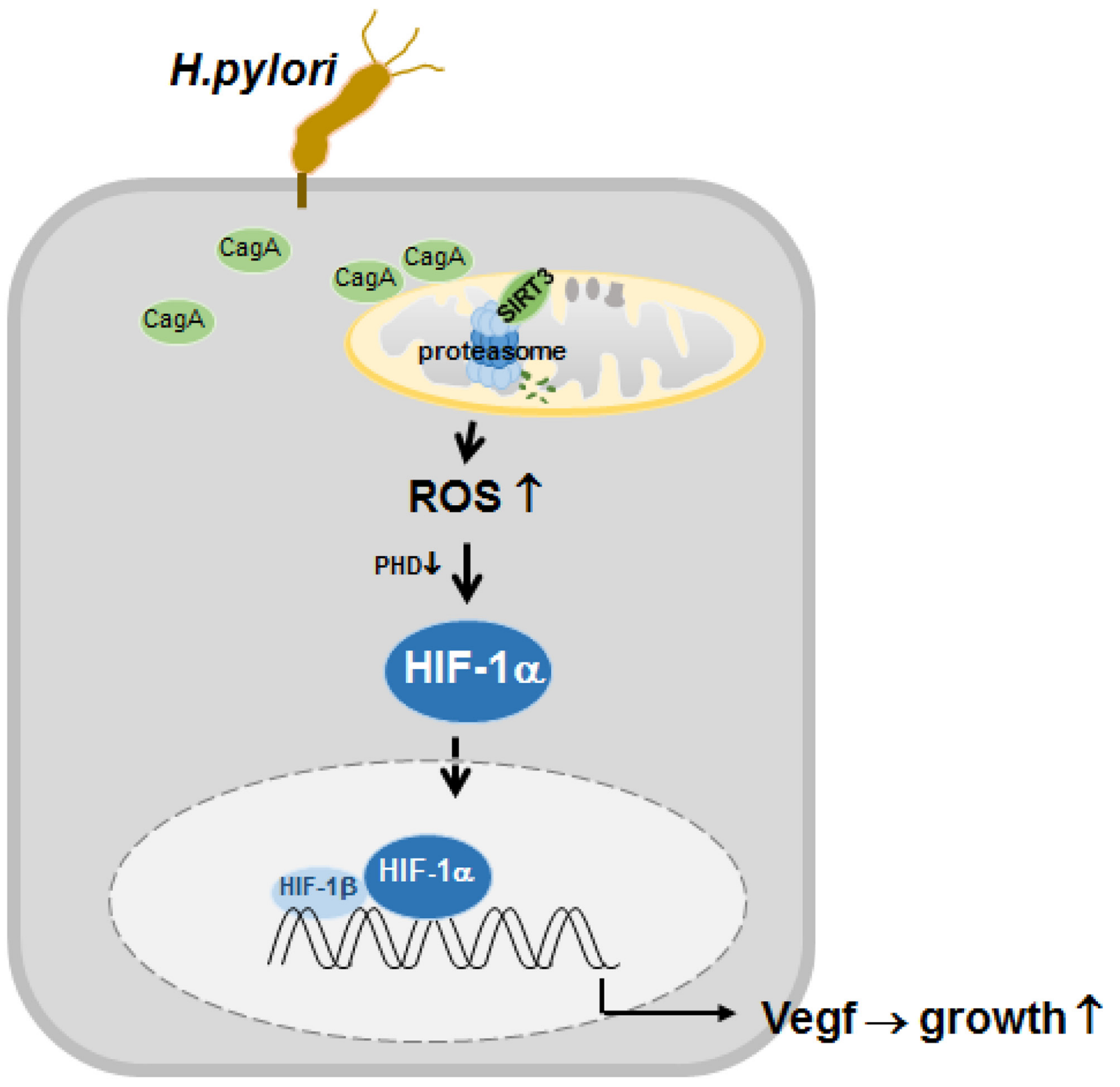

Figure 7: Proposed model depicting the regulation of HIF-1 $\alpha$ by downregulated SIRT3-mediated ROS production in H. pylori-infected gastric cells. Infection with H. pylori $\mathrm{CagA}^{+}$induces SIRT3 protein degradation by proteasome activity. Increased ROS generation from the downregulated SIRT3 activity mediates the activation of HIF-1 $\alpha$, and this, in turn, induces the expression of HIF$1 \alpha$ target genes, which leads to gastric cancer proliferation. 
confirmed that the gain of function of SIRT3 can recover the metabolic change in $H$. pylori infected gastric cancer cells. We found that HIF- $1 \alpha$ activity, ROS production, and HIF-1 $\alpha$ target gene expression were relatively decreased in SIRT3 overexpressing cells with $\mathrm{CagA}^{+} H$. pylori infection.

In conclusion, this study suggests that $H$. pylorimediated gastric carcinogenesis could be attributed to hypoxic activation of HIF-1 $\alpha$ activity via downregulation of mitochondrial SIRT3 in $\mathrm{CagA}^{+} H$. pylori-infected gastric cancer. SIRT3 may be a valuable effector molecule for gastric cancer prevention, as well as a potential treatment strategy.

\section{MATERIALS AND METHODS}

\section{Bacteria, cell culture, and infection with $H$. pylori}

The H. pylori strains used were 60190 (cagPAI $^{+}$, ATCC 49503), 8822 (cagPAI $\left.{ }^{-}\right), \Delta c a g A$ (an isogenic mutant of 60190 lacking $\operatorname{cag} A$ ), and $\triangle v a c A$ (an isogenic mutant of 60190 lacking vacA). H. pylori strains were cultured on agar plates containing $10 \%$ horse serum at $37^{\circ} \mathrm{C}$ in a microaerobic atmosphere, using the Campy Container System (BBL). Human gastric epithelial cells (AGS and MKN28) were cultured in RPMI-1640 medium (Gibco) supplemented with 10\% fetal bovine serum (FBS) and $1 \%$ penicillin-streptomycin sulfate. All cultures were maintained in a $37^{\circ} \mathrm{C}$ incubator supplemented with $5 \%$ $\mathrm{CO}_{2}$. Gastric epithelial cells were seeded in tissue culture plates at $48 \mathrm{~h}$ before infection and allowed to grow to approximately $80 \%$ confluence. At $2 \mathrm{~h}$ prior to infection, the medium was replaced by fresh medium containing $0.5 \%$ FBS. For infection, bacteria were harvested in phosphate-buffered saline (PBS) $(\mathrm{pH} \mathrm{7.4)}$ and added to the host cells at multiplicities of infection (MOIs) of 100 for varying times. Hypoxic conditions were generated by placing cells in a sealed hypoxic incubator (Thermo Scientific, MA, USA). The $\mathrm{O}_{2}$ level in this chamber was maintained at $1 \%$, with the residual gas mixture containing $5 \% \mathrm{CO}_{2}$ and $94 \% \mathrm{~N}_{2}$.

\section{Antibodies and chemicals}

Anti-HIF-1 $\alpha$, anti-CagA, anti-PHD1, antiPHD3, anti-Aldolase $\mathrm{A}$, anti-Lamin $\mathrm{B}$, and anti- $\beta$-actin were purchased from Santa Cruz Biotechnology, Inc. (Santa Cruz, CA, USA). An anti-HIF-1 $\alpha$ antibody was also purchased from BD Biosciences (San Jose, CA, USA). Anti-SIRT3, anti-PHD2, anti-Cox IV, and antihydroxylated-HIF-1 $\alpha$ were purchased from Cell Signaling Biotechnology (Danvers, MA, USA). The antioxidant inhibitors and chemicals were purchased from Sigma ( $\mathrm{St}$ Louis, MO, USA).

\section{Immunoblotting}

Whole cell extracts were prepared with RIPA buffer containing $50 \mathrm{mM}$ Tris ( $\mathrm{pH}$ 7.5), $1 \mathrm{mM}$ EDTA, $150 \mathrm{mM} \mathrm{NaCl}, 0.1 \%$ SDS, 0.1\% NaDeOC, 1\% NP-40, and complete protease inhibitor (Roche Applied Science). Lysates were separated by SDS-PAGE and transferred to polyvinylidene difluoride membranes (Millipore, Billerica, MA, USA). Membranes were incubated with appropriate primary antibodies overnight at $4^{\circ} \mathrm{C}$. Immunodetection was performed using an enhanced chemiluminescence reagent (Thermo Fisher Scientific), according to the manufacturer's instructions.

\section{Plasmids}

pcDAN3.1-SIRT3 Flag vector (No. 13814) was obtained from Addgene (Cambridge, MA, USA). To generate a lentiviral transfer vector with Flag-tagged SIRT3, pcDAN3.1-SIRT3 Flag vector was digested with restriction enzymes $\mathrm{BamHI}$ and $\mathrm{XbaI}$ and ligated into enzyme-digested pLVX-tight puro vector (Clontech, CA, USA). SIRT3 pLKO.1 shRNA vectors were purchased from Sigma (TRCN0000038892), and the control pLKO.1 scrambled vector was obtained from Addgene.

\section{Luciferase activity assay}

HRE-luc plasmid (graciously provided by Prof. L. Guarente) was used to measure HIF-mediated transcriptional activity. Cells $\left(3 \times 10^{5}\right)$ were plated into each well of a six-well plate and were transfected the next day using LipofectAMINE 2000 (Invitrogen) with $1 \mu \mathrm{g}$ of HREluciferase plasmid, containing three copies of HRE from the pgk-1 gene, and $0.05 \mu \mathrm{g}$ of pRL-TK plasmid. At $24 \mathrm{~h}$ after transfection, cells were infected with $H$. pylori or incubated in a hypoxia chamber. Subsequently, cells were lysed, and luciferase activities were measured using a dual-luciferase reporter assay kit (Promega, Madison, WI, USA) according to the manufacturer's protocol. Luciferase activity was measured using a luminometer (Berthold Technologies, Bad Wildbad, Germany). Values for firefly luciferase were normalized to Renilla ( $\mathrm{pRL}-\mathrm{TK}$ ) vector and presented as fold induction, compared to control.

\section{Real-time PCR}

Total RNA was isolated using TRIzol Reagent (Invitrogen) according to the manufacturer's instructions. Complementary DNA was produced with SuperScript II reverse transcriptase (Invitrogen, Carlsbad, CA, USA) at $42^{\circ} \mathrm{C}$ for $1 \mathrm{~h}$. The mixture was then boiled for $5 \mathrm{~min}$ to inactive reverse transcriptase and quickly chilled on ice. Synthesized cDNAs were analyzed by real-time PCR using SYBR Green master mix (Applied Biosystems, Foster City, CA, USA) and the ABI PRISM 7000 
Quantitative PCR system (Applied Biosystems). Each reaction was performed in triplicate, and the amounts of the PCR products produced were normalized with respect to $\beta$-actin.

\section{Subcellular fractionation}

Cytosolic and nuclear protein extraction: H. pyloriinfected AGS cells were harvested and separated into cytoplasmic and nuclear fractions using CEB buffer (10 mM Tris-HCl, pH 8, $60 \mathrm{mM} \mathrm{KCl,} 1 \mathrm{mM}$ EDTA, $1 \mathrm{mM}$ dithiothreitol), containing $0.5 \%$ Nonidet P-40 and protease inhibitors. The cytoplasmic fraction was clarified by centrifugation at $1200 \times g$ for $5 \mathrm{~min}$, and the nuclear pellet was washed with CEB buffer to remove cytoplasmic contamination. The nuclear pellet was lysed with NEB buffer $(20 \mathrm{mM}$ Tris-HCl, $\mathrm{pH} 8,0.4 \mathrm{M} \mathrm{NaCl}, 1.5 \mathrm{mM}$ $\mathrm{MgCl}_{2}, 1.5 \mathrm{mM}$ EDTA, $1 \mathrm{mM}$ dithiothreitol) containing $0.5 \%$ Nonidet P-40 and protease inhibitors. Nuclear proteins were analyzed by immunoblotting as described above.

Mitochondrial protein extraction: Mitochondrial and cytosolic fractions were extracted using a mitochondria isolation kit (Pierce Biotechnology, Inc., Rockford, IL, USA) following the manufacturer's protocol. The cytoplasmic fraction was concentrated by acetone precipitation, and isolated mitochondria were lysed with RIPA buffer. Then equal amounts of protein were subjected to direct immunoblot analysis.

\section{ROS determination}

Superoxide production was determined by measuring MitoSOX or DHE (dihydroethidium, Invitrogen) oxidation in cells, following the manufacturer's instructions. Cells were cultured as described above, and the cells were washed once with PBS and incubated for $20 \mathrm{~min}$ at $37^{\circ} \mathrm{C}$ in RPMI-1640 containing $5 \mu \mathrm{M}$ MitoSOX or $20 \mu \mathrm{M}$ DHE before being trypsinized, resuspended, and measured by flow cytometry. For confocal immunofluorescence microscopy, H. pylori-infected cells were stained with MitoSOX $(5 \mu \mathrm{M})$ for $20 \mathrm{~min}$ at $37^{\circ} \mathrm{C}$, washed with PBS, and counterstained with mounting medium for fluorescence. Slides were sealed with coverslips and examined for immunofluorescence using a confocal laserscanning microscope (LSM 700; Carl Zeiss, Thornwood, NY, USA).

\section{Immunofluorescence microscopy}

H. pylori-infectedAGS cells were stained with Mitotracker for $30 \mathrm{~min}$ at $37^{\circ} \mathrm{C}$, fixed in ice-cold methanol for $10 \mathrm{~min}$, and washed with PBS. Nonspecific binding was blocked with $3 \%$ bovine serum albumin (BSA) in PBS for $30 \mathrm{~min}$, followed by incubation with anti-CagA rabbit polyclonal antibody in $2 \% \mathrm{BSA}$ in $\mathrm{PBS}$ at $4{ }^{\circ} \mathrm{C}$ overnight. After washing with PBS, CagA was visualized by treatment with fluorescein isothiocyanate-conjugated goat anti-rabbit polyclonal secondary antibody for 60 min at room temperature. Cells were washed with PBS, mounting medium for fluorescence was added, and the slides were sealed with coverslips before examination for immunofluorescence using a confocal laser-scanning microscope.

\section{SIRT3 enzymatic activity assay}

SIRT3 enzymatic activity was assayed with the Fluorogenic SIRT3 assay kit (BPS Bioscience, CA, USA) following the manufacturer's instructions, with slight modifications. Mitochondrial protein $(1 \mu \mathrm{g})$ was incubated at $37^{\circ} \mathrm{C}$ for $45 \mathrm{~min}$ with specific substrates; $25 \mu \mathrm{l}$ of developer was added; and after $45 \mathrm{~min}$ of incubation, SIRT3 activity was measured using a fluorimetric microplate reader at $360 \mathrm{~nm} / 460 \mathrm{~nm}$.

\section{Immunohistochemical staining}

To quantify angiogenesis, microvessel density was determined by counting CD31-positive vessels. Tissues from nude mice were fixed overnight in formalin at $4{ }^{\circ} \mathrm{C}$ and embedded in paraffin. Tissue sections were deparaffinized with xylene, hydrated in serial dilutions of alcohol, and immersed in $3 \% \mathrm{H}_{2} \mathrm{O}_{2}$. Following antigen retrieval by heat mediation in a Tris/EDTA buffer $(\mathrm{pH} 9)$ solution, the tissue sections were incubated with proteinblocking agent (Immunotech, Marseille, France) to block nonspecific antibody binding for $30 \mathrm{~min}$ at room temperature and then incubated overnight at $4^{\circ} \mathrm{C}$ with primary antibody against anti-CD31 (Abcam, 1:200) in a humidified chamber. After washing with PBS three times, the sections were incubated with a biotinylated secondary antibody and streptavidin conjugated to horseradish peroxidase (Immunotech) for $60 \mathrm{~min}$ at room temperature, followed by a PBS wash. The chromogen was developed for various times with liquid 3,3'-diaminobenzidine (Immunotech) followed by counterstaining with Meyer's hematoxylin. Slides were examined under a light microscope.

\section{Xenografts}

First, $5 \times 10^{6}$ AGS cells were resuspended in $100 \mu \mathrm{l}$ of serum-free RPMI-1640 medium with Matrigel and then injected subcutaneously into either flank of six-week-old BALB/c nude mice (OrientBio, Kapyoung, Korea). For the doxycycline-treated tumor group, AGS cells expressing SIRT3 were first treated with doxycycline $(2 \mu \mathrm{g} / \mathrm{ml})$ for 2 days to induce SIRT3 expression. $5 \times 10^{6}$ of these cells in $100 \mu \mathrm{l}$ serum-free RPMI-1640 medium with Matrigel were injected into the nude mice. After injection, mice were given doxycycline $(1 \mathrm{mg} / \mathrm{ml})$ with drinking water for three months. The bottles of water were changed weekly. The tumors were measured weekly by calipers, 
and their volumes were calculated as $\mathrm{V}=\mathrm{L} \times \mathrm{W}^{2} \times 0.5$ (length L and width W). At the end of the experiment, mice were sacrificed and tumors were weighed. Tissues were removed for RT-PCR, immunoblotting, and IHC.

\section{Statistical analysis}

Statistical analyses were performed using SPSS 18.0 software. All values are expressed as the mean \pm standard deviation. Comparisons between two groups were analyzed using t-tests, and one-way ANOVA with a post hoc Bonferroni test was used for multiple comparisons. $P$-values $<0.05$ were considered statistically significant.

\section{ACKNOWLEDGMENTS}

We would like to thank Prof. L. Guarente for providing HRE-luc plasmid.

\section{CONFLICTS OF INTEREST}

Authors declare no potential conflicts of interest.

\section{GRANT SUPPORT}

This research was supported by Basic Science Research Program through the National Research Foundation of Korea (NRF) funded by the Ministry of Education, Science and Technology (NRF-2013R1A1A2010591) and a faculty research grant of Yonsei University College of Medicine (6-2014-0130).

\section{REFERENCES}

1. Harris AL. Hypoxia - a key regulatory factor in tumour growth. Nat Rev Cancer. 2002; 2:38-47

2. Handa O, Naito Y, Yoshikawa T. Redox biology and gastric carcinogenesis: the role of Helicobacter pylori. Redox Rep. $2011 ; 16: 1-7$

3. Hayashi T, Senda M, Morohashi H, Higashi H, Horio M, Kashiba Y, Nagase L, Sasaya D, Shimizu T, Venugopalan N, Kumeta H, Noda NN, Inagaki F, et al. Tertiary structurefunction analysis reveals the pathogenic signaling potentiation mechanism of Helicobacter pylori oncogenic effector CagA. Cell Host Microbe. 2012; 12:20-33.

4. Backert S, Tegtmeyer N, Selbach M. The versatility of Helicobacter pylori CagA effector protein functions: the master key hypothesis. Helicobacter. 2010; 15:163-76.

5. Suzuki H, Suzuki M, Mori M, Kitahora T, Yokoyama H, Miura S, Hibi T, Ishii H. Augmented levels of gastric mucosal leucocyte activation by infection with cagA gene-positive Helicobacter pylori. J Gastroenterol Hepatol. 1998; 13:294-3000.

6. Semenza GL. HIF-1: upstream and downstream of cancer metabolism. Curr Opin Genet Dev. 2010; 20:51-56.
7. Semenza GL. HIF-1 and tumor progression: pathophysiology and therapeutics. Trends Mol Med. 2002 (Suppl); 8:S62-67.

8. Brunelle JK, Bell EL, Quesada NM, Vercauteren K, Tiranti V, Zeviani M, Scarpulla RC, Chandel NS. Oxygen sensing requires mitochondrial ROS but not oxidative phosphorylation. Cell Metab. 2005; 1:409-14.

9. Guzy RD, Hoyos B, Robin E, Chen H, Liu L, Mansfield KD, Simon MC, Hammerling U, Schumacker PT. Mitochondrial complex III is required for hypoxia-induced ROS production and cellular oxygen sensing. Cell Metab. 2005; 1:401-08.

10. Taylor DM, Maxwell MM, Luthi-Carter R, Kazantsev AG. Biological and potential therapeutic roles of sirtuin deacetylases. Cell Mol Life Sci. 2008; 65:4000-18.

11. Imai S, Armstrong CM, Kaeberlein M and Guarente L. Transcriptional silencing and longevity protein Sir2 is an NAD-dependent histone deacetylase. Nature. 2000; 403:795-800.

12. Saunders LR, Verdin E. Sirtuins: critical regulators at the crossroads between cancer and aging. Oncogene. 2007; 26:5489-504.

13. Michan S, Sinclair D. Sirtuins in mammals: insights into their biological function. Biochem J. 2007; 404:1-13.

14. Michishita E, Park JY, Burneskis JM, Barrett JC, Horikawa I. Evolutionarily conserved and nonconserved cellular localizations and functions of human SIRT proteins. Mol Biol Cell. 2005; 16:4623-35.

15. Hirschey MD, Shimazu T, Goetzman E, Jing E, Schwer B, Lombard DB, Grueter CA, Harris C, Biddinger S, Ilkayeva OR, Stevens RD, Li Y, Saha AK, et al. SIRT3 regulates mitochondrial fatty-acid oxidation by reversible enzyme deacetylation. Nature. 2010; 464:121-25.

16. Qiu X, Brown K, Hirschey MD, Verdin E, Chen D. Calorie restriction reduces oxidative stress by SIRT3-mediated SOD2 activation. Cell Metab. 2010; 12:662-67.

17. Lombard DB, Alt FW, Cheng HL, Bunkenborg J, Streeper RS, Mostoslavsky R, Kim J, Yancopoulos G, Valenzuela D, Murphy A, Yang Y, Chen Y, Hirschey MD, et al. Mammalian Sir2 homolog SIRT3 regulates global mitochondrial lysine acetylation. Mol Cell Biol. 2007; 27:8807-14.

18. Tao R, Coleman MC, Pennington JD, Ozden O, Park SH, Jiang H, Kim HS, Flynn CR, Hill S, Hayes McDonald W, Olivier AK, Spitz DR, Gius D. Sirt3-mediated deacetylation of evolutionarily conserved lysine 122 regulates MnSOD activity in response to stress. Mol Cell. 2010; 40:893-904.

19. Finley LW, Carracedo A, Lee J, Souza A, Egia A, Zhang J, Teruya-Feldstein J, Moreira PI, Cardoso SM, Clish CB, Pandolfi PP, Haigis MC. SIRT3 opposes reprogramming of cancer cell metabolism through HIF $1 \alpha$ destabilization. Cancer Cell. 2011; 19:416-28.

20. Lu X, Bennet B, Mu E, Rabinowitz J, Kang Y. Metabolomic changes accompanying transformation and acquisition of 
metastatic potential in a syngeneic mouse mammary tumor model. J Biol Chem. 2010; 285:9317-21.

21. Kim HS, Patel K, Muldoon-Jacobs K, Bisht KS, AykinBurns N, Pennington JD, van der Meer R, Nguyen P, Savage J, Owens KM, Vassilopoulos A, Ozden O, Park SH, et al. SIRT3 is a mitochondria-localized tumor suppressor required for maintenance of mitochondrial integrity and metabolism during stress. Cancer Cell. 2010; 17:41-52.

22. Bell EL, Emerling BM, Ricoult SJ, Guarente L. SirT3 suppresses hypoxia inducible factor $1 \alpha$ and tumor growth by inhibiting mitochondrial ROS production. Oncogene. 2011; 30:2986-96.

23. Chandel NS, Maltepe E, Goldwasser E, Mathieu CE, Simon MC, Schumacker PT. Mitochondrial reactive oxygen species trigger hypoxia-induced transcription. Proc Natl Acad Sci USA. 1998; 95:11715-20.

24. Cross AR, Jones OT. The effect of the inhibitor diphenylene iodonium on the superoxide-generating system of neutrophils. Specific labelling of a component polypeptide of the oxidase. Biochem J. 1986; 237:111-16.

25. Doussière J, Vignais PV. Diphenylene iodonium as an inhibitor of the NADPH oxidase complex of bovine neutrophils. Factors controlling the inhibitory potency of diphenylene iodonium in a cell-free system of oxidase activation. Eur J Biochem. 1992; 208:61-71.

26. Holland PC, Clark MG, Bloxham DP, Lardy HA. Mechanism of action of the hypoglycemic agent diphenyleneiodonium. J Biol Chem. 1973; 248:6050-56.

27. Ragan CI, Bloxham DP. Specific labelling of a constituent polypeptide of bovine heart mitochondrial reduced nicotinamide-adenine dinucleotide-ubiquinone reductase by the inhibitor diphenyleneiodonium. Biochem J. 1977; 163:605-15.

28. Starkov AA, Fiskum G. Myxothiazol induces $\mathrm{H}(2) \mathrm{O}(2)$ production from mitochondrial respiratory chain. Biochem Biophys Res Commun. 2001; 281:645-50.

29. Asher G, Lotem J, Sachs L, Kahana C, Shaul Y. Mdm-2 and ubiquitin-independent p53 proteasomal degradation regulated by NQO1. Proc Natl Acad Sci USA. 2002; 99:13125-30.

30. Yonashiro R, Sugiura A, Miyachi M, Fukuda T, Matsushita N, Inatome R, Ogata Y, Suzuki T, Dohmae N, Yanagi S. Mitochondrial ubiquitin ligase MITOL ubiquitinates mutant SOD1 and attenuates mutant SOD1-induced reactive oxygen species generation. Mol Biol Cell. 2009; 20:4524-30.

31. Handa O, Naito Y, Yoshikawa T. CagA protein of Helicobacter pylori: a hijacker of gastric epithelial cell signaling. Biochem Pharmacol. 2007; 73:1697-702.

32. Berra E, Benizri E, Ginouvès A, Volmat V, Roux D, Pouysségur J. HIF prolyl-hydroxylase 2 is the key oxygen sensor setting low steady-state levels of HIF-1alpha in normoxia. EMBO J. 2003; 22:4082-90.
33. Kusters JG, van Vliet AH, Kuipers EJ. Pathogenesis of Helicobacter pylori infection. Clin Microbiol Rev. 2006; 19:449-90.

34. Isomoto $\mathrm{H}$, Moss J, Hirayama T. Pleiotropic actions of Helicobacter pylori vacuolating cytotoxin, VacA. Tohoku J Exp Med. 2010; 220:3-14.

35. Telford JL, Ghiara P, Dell'Orco M, Comanducci M, Burroni D, Bugnoli M, Tecce MF, Censini S, Covacci A, Xiang Z, et al. Gene structure of the Helicobacter pylori cytotoxin and evidence of its key role in gastric disease. J Exp Med. 1994; 179:1653-58.

36. Galmiche A, Rassow J. Targeting of Helicobacter pylori VacA to mitochondria. Gut Microbes. 2010; 1:392-95.

37. Cover TL, Krishna US, Israel DA, Peek RM Jr. Induction of gastric epithelial cell apoptosis by Helicobacter pylori vacuolating cytotoxin. Cancer Res. 2003; 63:951-57.

38. Kim JM, Kim JS, Lee JY, Kim YJ, Youn HJ, Kim IY, Chee YJ, Oh YK, Kim N, Jung HC, Song IS. Vacuolating cytotoxin in Helicobacter pylori water-soluble proteins upregulates chemokine expression in human eosinophils via $\mathrm{Ca} 2+$ influx, mitochondrial reactive oxygen intermediates, and NF-kappaB activation. Infect Immun. 2007; 75:3373-81.

39. Kruman II, Mattson MP. Pivotal role of mitochondrial calcium uptake in neural cell apoptosis and necrosis. J Neurochem. 1999; 72:529-40.

40. van de Water B, Zoeteweij JP, de Bont HJ, Mulder GJ, Nagelkerke JF. Role of mitochondrial $\mathrm{Ca} 2+$ in the oxidative stress-induced dissipation of the mitochondrial membrane potential. Studies in isolated proximal tubular cells using the nephrotoxin 1,2-dichlorovinyl-L-cysteine. J Biol Chem. 1994; 269:14546-52.

41. Borutaite V, Morkuniene R, Brown GC. Release of cytochrome $\mathrm{c}$ from heart mitochondria is induced by high $\mathrm{Ca} 2+$ and peroxynitrite and is responsible for $\mathrm{Ca}(2+)$ induced inhibition of substrate oxidation. Biochim Biophys Acta. 1999; 1453:41-48.

42. Mori M, Suzuki H, Suzuki M, Kai A, Miura S, Ishii H. Catalase and superoxide dismutase secreted from Helicobacter pylori. Helicobacter. 1997; 2:100-05.

43. Griffiths EA, Pritchard SA, Valentine HR, Whitchelo N, Bishop PW, Ebert MP, Price PM, Welch IM, West CM. Hypoxia-inducible factor-1alpha expression in the gastric carcinogenesis sequence and its prognostic role in gastric and gastro-oesophageal adenocarcinomas. $\mathrm{Br} \mathrm{J}$ Cancer. 2007; 96:95-103.

44. Tuccillo C, Cuomo A, Rocco A, Martinelli E, Staibano S, Mascolo M, Gravina AG, Nardone G, Ricci V, Ciardiello F, Del Vecchio Blanco C, Romano M. Vascular endothelial growth factor and neo-angiogenesis in $\mathrm{H}$. pylori gastritis in humans. J Pathol. 2005; 207:277-84.

45. Grune T, Reinheckel T, Joshi M, Davies KJ. Proteolysis in cultured liver epithelial cells during oxidative stress. Role 
of the multicatalytic proteinase complex, proteasome. J Biol Chem. 1995; 270:2344-51.

46. Grune T, Reinheckel T, Davies KJ. Degradation of oxidized proteins in K562 human hematopoietic cells by proteasome. J Biol Chem. 1996; 271:15504-09.
47. Grune T, Reinheckel T, Davies KJ. Degradation of oxidized proteins in mammalian cells. FASEB J. 1997; 11:526-34. 